\title{
Livelihood resilience in the face of recurring floods: an empirical evidence from Northwest Ethiopia
}

\author{
Zerihun Berhane Weldegebriel ${ }^{1 *}$ and Befikadu Esayas Amphune ${ }^{2}$
}

\begin{abstract}
Background: The recent trend of increasing incidents of floods in Ethiopia is disrupting the livelihoods of a significant proportion of the country's population. This study assesses the factors that shape the resilience and the vulnerability of rural households in the face of recurring floods by taking the case of Dembia district of Northwest Ethiopia as one of the flood-prone areas in the country.

Results: The data for the study were collected through a survey of 284 households, two focus group discussions, and 12 key informant interviews. Principal Component Analysis and simple linear regression were used for the analysis. The former served both for data reduction and identification of the dominant factors that explain resilience to recurring flood hazards while the latter was used to check the relationship between resilience and vulnerability. Findings indicate that access and use of livelihood resources such as size of farmlands, availability of farm oxen, credit as well as ability to draw help from social networks were found to be the most important factors that determine the resilience of households to floods. Similarly, the coping strategies employed by households were found to be constrained mainly by the scale and impact of the recent floods and lack or shortage of basic infrastructural and social facilities.

Conclusions: The results confirmed that most of the traditional coping strategies employed by households failed to effectively help households offset the impacts of flooding. Given the livelihood context of smallholder farming system in the studied area, context specific institutional interventions such as the integrated use of both safety nets and cargo nets may help communities to overcome livelihood predicaments associated with the recurrent flood disasters. This implies that policy should focus more on addressing the factors that expose people to flood disasters and shape their resilience, rather than focusing on short-term emergency responses which seems to be the norm in much of the flood affected areas in the country.
\end{abstract}

Keywords: Flood disaster, Resilience index, Vulnerability index, Dembia, Northwest Ethiopia

\section{Background}

It is widely recognized that environmental hazards frequently affect the livelihoods of many people around the world. The effects of these hazards cannot be expected to be similar as people and nations differ in terms of their level of development, which largely determines their response to specific disasters.

Flooding is one of the most frequent and destructive environmental hazards that occur annually worldwide (United Nations International strategy for Disaster

\footnotetext{
* Correspondence: zerihun.berhane@aau.edu.et

${ }^{1}$ Center for African and Oriental Studies, Addis Ababa University, P.O. Box:

1176, Addis Ababa, Ethiopia

Full list of author information is available at the end of the article
}

Reduction [UNISDR] (2015). The frequency and severity of flooding are also increasing in many parts of the world associated with population pressure, urbanization and climate change (Hirabayashi et al., 2013; Jongman et al., 2014). This is evident when one considers the number of people affected by flooding in recent decades. For instance, flooding accounts much of the loss event worldwide between 1980-2014 more than any other single disaster (Munich RE, 2015) and tops the list of natural disasters by economic damages in 2014 (Guha-Sapir et al., 2015). Flooding is also the leading disaster agent in the world in terms total number of reported disasters from 1900-2014 (see Additional file 1: Figure A) while it is the second largest natural hazard, next to drought, in 
terms of total number of affected persons between 1960 and 2015 (see Additional file 1: Figure B).

In Ethiopia, despite being given relatively less attention as compared to drought, flooding has long been recognized as one of the major environmental hazards that often develop into a disaster affecting the lives and livelihoods of people for many years. In fact, flooding and its damages are considered as a perennial phenomenon in the highlands (Disaster Prevention and Preparedness Commission [DPPC], 1994). The country's proneness to non-drought disasters such as floods has been limited in the past in terms of frequency and scope (DPPC, 1997a).

However, the historical records on flood data suggests that Ethiopia faced 47 major floods since 1900, which affected close to 2.2 million people (You and Ringer, 2010). In this regard, many of the flood disasters occurred since 1980 (World Bank, 2010) (see also Table 1). This coupled with climate change and variability is likely to increase flooding as one of the major extreme events in the future posing a growing threat to many livelihoods (Intergovernmental Panel on Climate Change (IPCC), 2014; Savage et al., 2015). Flooding as a recurrent environmental hazard is particularly felt in areas where people are already vulnerable to any adverse climatic event as a result of weakened resilience. For instance, an estimated 210,600 people were affected by flooding only within three months (November, 2015January, 2016) (United Nations Office for the Coordination of Humanitarian Affairs [UN-OCHA], 2016 p.1)

A complete national and regional disaggregated data on flood disasters is limited in Ethiopia (see Table 2). However, the available literature indicates that some areas in the country are far more frequently affected than others, to the extent of being labeled as 'floodprone areas' (World Meteorological Organization (WMO), 2003; Nederveen et al., 2011; UN-OCHA, 2016). These areas include central and western zones of

Table 1 Total damage due to natural disasters between 1900 and 2013 in Ethiopia

\begin{tabular}{lll}
\hline Year & Type & Total damage ('O00 US\$) \\
\hline 1906 & Earthquake & 6750 \\
1969 & Drought & 1000 \\
1973 & Drought & 76,000 \\
1994 & Flood & 3500 \\
1998 & Drought & 15,600 \\
1999 & Flood & 2700 \\
2005 & Flood & 5000 \\
2005 & Flood & 1200 \\
2006 & Flood & 3200 \\
2013 & Flood & 2200 \\
\hline
\end{tabular}

Source: Authors' computation from EM-DAT: OFDA/CRED International Disaster Database-http://www.emdat.be/
Table 2 Flood Disaster Statistics in Ethiopia between 1960 and 2013

\begin{tabular}{|c|c|c|c|c|c|}
\hline Year & Occurrence & Total deaths & Affected & Homeless & Total affected \\
\hline 1968 & 1 & 1 & 10,000 & 6000 & 16,000 \\
\hline 1976 & 1 & 0 & 50,000 & 20,000 & 70,000 \\
\hline 1977 & 1 & 7 & 16,000 & 0 & 16,000 \\
\hline 1978 & 1 & 9 & 1000 & 0 & 1000 \\
\hline 1981 & 1 & 0 & 20,000 & 0 & 20,000 \\
\hline 1985 & 2 & 9 & 8000 & 20,000 & 28,000 \\
\hline 1988 & 2 & 45 & 47,240 & 0 & 47,240 \\
\hline 1990 & 1 & 0 & 350,000 & 0 & 350,000 \\
\hline 1993 & 2 & 2 & 30,000 & 4800 & 34,800 \\
\hline 1994 & 1 & 4 & 43,000 & 0 & 43,014 \\
\hline 1995 & 1 & 27 & 93,875 & 0 & 93,875 \\
\hline 1996 & 2 & 40 & 90,000 & 25,000 & 115,000 \\
\hline 1997 & 2 & 326 & 65,000 & 0 & 65,022 \\
\hline 1999 & 6 & 48 & 22,255 & 125,000 & 147,255 \\
\hline 2000 & 2 & 69 & 30,000 & 0 & 30,000 \\
\hline 2001 & 3 & 5 & 39,500 & 0 & 39,500 \\
\hline 2002 & 1 & 22 & 4000 & 0 & 4000 \\
\hline 2003 & 1 & 119 & 110,000 & 0 & 110,000 \\
\hline 2005 & 4 & 211 & 242,418 & 0 & 242,418 \\
\hline 2006 & 7 & 951 & 434,050 & 0 & 434,146 \\
\hline 2007 & 2 & 17 & 245,386 & 0 & 245,386 \\
\hline 2008 & 3 & 45 & 115,595 & 810 & 116,440 \\
\hline 2010 & 2 & 19 & 80,700 & 0 & 80,700 \\
\hline 2011 & 1 & 0 & 40,200 & 0 & 40,200 \\
\hline 2013 & 1 & 0 & 51,500 & 0 & 51,500 \\
\hline
\end{tabular}

Source: Authors' computation from EM-DAT: OFDA/CRED International Disaster Database-www.emdat.be

Tigray; North Gondar, North and South Wello, and Oromia zones of Amhara region which are often affected by flash flooding as well as those that are affected by riverine floods, which include almost all the major river basins and the Tana Basin (DPPC 1994; 1997b; Nederveen et al., 2011; UN-OCHA, 2016).

The Amhara region as indicated above is one of the flood-prone areas in the country where severe and frequent floods affect a considerable number of people in recent years. In this regard, the limited available data on the effects of floods in the region indicate that riverine floods were recorded in 1966, 1967, 1974, and 1975. Severe flash floods have also been recorded in 1993 and 1996, with 72,569 people being affected. And a severe flooding in 2006, has affected 107,286 people, displacing 37,982, damaging crops on 18,000 ha of land in six zones (Disaster Prevention and Preparedness Agency [DPPA], 2007; Nederveen et al., 2011; UN-OCHA 2016). Moreover, seven districts in the region, which are all found 
around Lake Tana, are particularly well known for being frequently affected by both flash and riverine floods. One of these areas is Dembia district in North Gondar zone, which is highly affected by Megech, Derema and Gumero rivers that frequently overflow their banks affecting the nearby settled plains (DPPA, 2007) (see Additional file 1: Table A).

Flooding in Dembia district, has become all too common in recent years, and remains the most serious challenge to peoples' livelihood with its short and long-term effects. As a result, some people were forced into destitution (UN-OCHA, 2006; DPPA, 2007; You and Ringer, 2010; Kreft et al., 2016; UN-OCHA, 2016). When this, coupled with the increasing flooding scenario predicted by the reports of the IPPC $(2007 ; 2012 ; 2014)$ amplify the magnitude of the problem. Furthermore, the problem of flooding would particularly be worse for countries like Ethiopia with the majority of its population subjected to poverty and vulnerability to climatic shocks (Berhanu and Fekadu, 2015; Ethiopian Panel on Climate Change [EPCC], 2015; Savage et al., 2015). This in turn, justifies the need to study flooding as a livelihood problem since it creates downward pressures on livelihoods. The understanding of flooding as a livelihood shock also needs an analysis of resilience of livelihood systems in the face of the recurring flood disasters.

The concept of resilience has recently been widely promoted in many fields such as engineering, psychology, and ecology, very recently resilience has become widely used by humanitarian and development actors working across diverse thematic areas including, disaster risk reduction, climate change, ecosystem management, and food and nutrition security (Frankenberger et al., 2012; Constas and Barrett, 2013; Maxwell et al., 2013; Hoddinott, 2014; Razafindrabe et al., 2015). Building resilience of households, communities, and systems has also been considered as a crucial policy objective among various development frameworks including, the Sendai Framework for Disaster Risk Reduction (United Nations [UN], 2015a), the Paris Agreement on Framework Convention on Climate Change (UN, 2015b), and the Sustainable Development Goals (UN, 2015c). Resilience harbors different meanings in different contexts. In disaster risk reduction, it is broadly viewed as a concept that deals with a system's capacity to anticipate, to cope, to absorb, adapt to, and recover from the adverse impact of hazards and reduce vulnerability (Razafindrabe et al., 2015; Tanner et al., 2015). The concept of vulnerability is often contrasted with resilience; however, it is an interlinked function of exposure, sensitivity, and adaptive capacity (Adger, 2006; IPCC, 2014). Being a common indicator, adaptive capacity, can be taken as a desirable characteristic of a system that minimizes vulnerability while enhances resilience at all levels (Engle, 2011;
Frankenberger and Nelson, 2013). Following Maru et al. (2014), this study argues that there is a need to combine the two concepts since both are concerned with features that affect people's ability to cope with and respond to change.

In dealing with resilience, it is important to define "resilience to whom" and "resilience of what" (Cutter, 2016 p.1). Accordingly, livelihood resilience as the building block of this study is conceptualized as "the capacity of all people across generations to sustain and improve their livelihood opportunities and well-being despite environmental, economic, social, and political disturbances" (Tanner et al., 2015 p.1). However, one of the main deficiencies in the literature so far has been the failure to identify the root causes of vulnerability as an initial step to understanding resilience owing to disciplinary perspectives and focus limited dimensions (Cutter, 2016). This in turn resulted in lack of working definitions, key indicators, and valid measurements for the concepts of vulnerability and resilience in the literature (Alfani et al., 2015; Bahadur et al., 2015; Razafindrabe et al., 2015; Cutter, 2016).

Most studies conducted on natural disasters and their effects on peoples' livelihoods in different parts of Ethiopia focused mainly on drought and overlooked flooding and its impacts (Woldemariam, 1986; Rahmato, 1991; Sharp et al., 2003; Rahmato, 2007). The few available studies on floods also focus on issues such as risk perceptions and risk management strategies (Moges, 1978; Bekele, 2003; WMO, 2003; Nederveen et al., 2011). Although there are recent studies that looked into resilience and vulnerability in Ethiopia, flooding and its impact on livelihoods has not been investigated (Deressa et al., 2008; Simane et al., 2014; Mengistu et al., 2015). This is a key gap in the existing empirical studies given that flooding is a major natural hazard that affects the livelihoods of thousands of smallholder farming communities every year across the country (see also Table 2).

This study therefore addresses the gap in the literature by looking into the root causes of vulnerability and measuring livelihood resilience of smallholder farmers to flood hazards. Linking livelihood approaches to resilience thinking is imperative to enhance the understanding of livelihood dynamics and to explore how households maintain and improve their livelihoods in the face of natural disasters (Scoones, 2009; Sallu et al., 2010). In view of this, the study contributes to the disaster risk reduction literature by providing empirical evidences on the determinants of vulnerability and resilience to the recurring flood hazards. The study also adds to the conceptual and methodological debates surrounding vulnerability and resilience by focusing on the least studied hazard in Ethiopia and developing and applying context-specific indices. This would further 
contribute to the application of relevant measurements in relation to capturing the multidimensional nature of both vulnerability and resilience. Finally, the study highlights the synergy between the vulnerability and resilience $^{1}$, which need to be fostered, if the objective of achieving Sustainable Development Goals (SDGs) in rural parts of developing countries is to be addressed in years to come (Fig. 1).

\section{Methods}

\section{Research design}

A quantitative-dominant, qualitative mixed research design was employed, where the quantitative data and qualitative information were collected concurrently. This approach helped the study to assess how vulnerability and resilience are conceived in local contexts, examine locally-specific impacts of flooding, and factors that shape the resilience of households in the face of this disaster.

\section{Data sources}

Quantitative data and qualitative information for this study were obtained from both primary and secondary sources. A cross-sectional survey of 284 farm households was supplemented by qualitative information from 12 Key Informant Interviews (KIIs), two Focus Group Discussions (FGDs), field observations, and Participatory Rural Appraisal (PRA) tools including problem ranking and scoring exercises. These data were obtained between March-May, 2015.

\section{Sampling and sample size}

In selecting the sample households for the survey, a multistage sampling procedure was employed. In stage one, eight Kebeles ${ }^{2}$ were selected from the 40 rural Kebeles in the district purposively as they are frequently hit by seasonal flooding. In stage two, two Kebeles (Tana Weyna and Gur-Amba) out of the eight flood prone Kebeles were selected purposively using pre-defined criteria. The criteria include, the physical proximity to flood hazard source particularly to the nearby rivers (location and exposure) and the severity and frequency of flood-disasters. ${ }^{3}$ After selecting the two Kebeles, a list of the households in 26 villages (15 in Tana Weyna and 11 in Gura-Amba) was recompiled and used as a sampling frame to select the households. Thus, a final sample of 256 households out of the 971 households were selected using systematic random sampling technique. ${ }^{4}$

For the qualitative interviews, both KIIs and FGD participants were selected purposively using criteria that includes being born in a particular village or lived there for not less than two decades; have a first-hand experience of flood disasters; and being knowledgeable about the local environment, weather patterns and climate. This was meant to capture the spatio-temporal perspectives

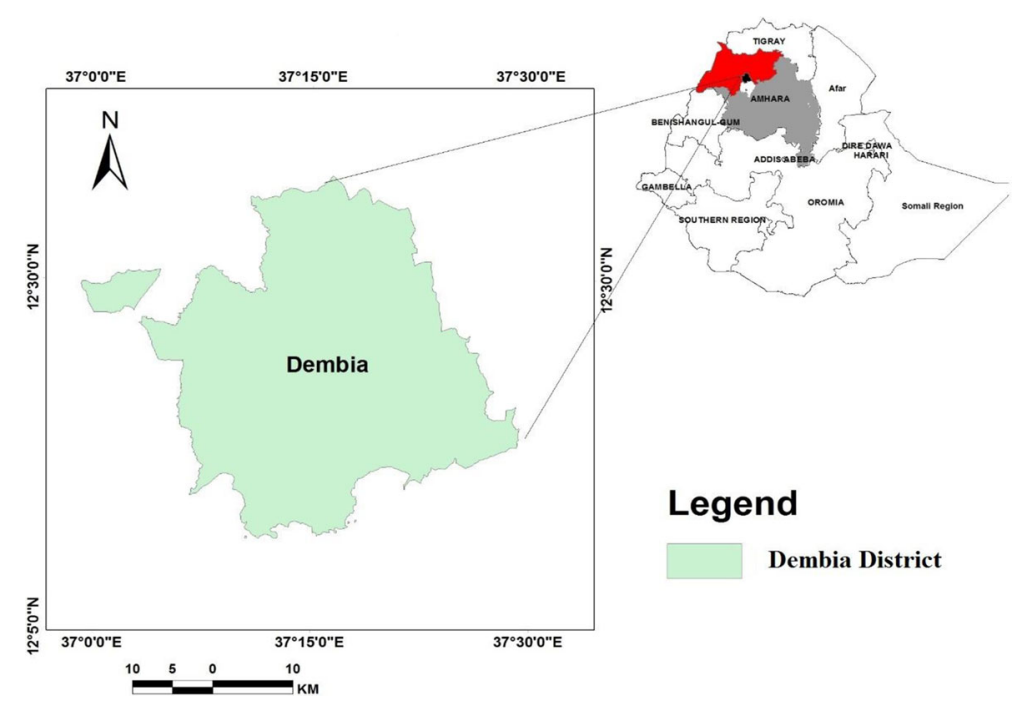

Fig. 1 Location of the study district The map shows Dembia district of the Amhara region, Northwestern Ethiopia. It is located at $12^{\circ} 18^{\prime} 30^{\prime \prime} \mathrm{N}$ and $37^{\circ} 17^{\prime} 30 " E$ (see Fig. 1). It has an area of the 148,968 ha from which plain land accounts for about $87 \%$, mountain and hills $5 \%$, valleys and gorges $4.8 \%$ and water bodies 3.2\%. The altitude of the district ranges from 1850 to 2000 m.a.s.l. Therefore, it is predominantly classified as Mid-land agro-ecology and the slope ranges from 2 to 4\%. The district on average receives an annual rainfall between $700 \mathrm{~mm}$ to $1160 \mathrm{~mm}$. Belg (the short rains February-April) and Meher (the long rains June-September). The average yearly minimum and maximum temperature is $18{ }^{\circ} \mathrm{C}$ and $28^{\circ} \mathrm{C}$ respectively. Based on the recent Central Statistical Authority's (CSA) population projection, the district had an estimated total population of 307,967 (CSA, 2013 ). Out of this total population, the majority, about 90\%, are rural residents with an average agricultural household size of six persons. Source: Authors' based on Ethio-Geographic Information System (GIS) and (CSA, 2007) 
of the studied households and communities about flood disasters based on recall.

\section{Data collection instruments}

A structured survey questionnaire was designed and piloted in order to generate information on households' socio-economic and demographic characteristics, livelihood asset profiles, livelihood activities, and income portfolios. The questionnaire also consisted questions related to households' vulnerability situations, including indicators relating to exposure, sensitivity, and adaptive capacity. Moreover, questions pertaining to absorptive and transformative capacities of resilience were added while adaptive capacity indicators were used as common indicators for both vulnerability and resilience. Both interview guides and discussion checklists were designed to gather qualitative information to supplement the household survey. Smallholder farmers, community members, government and non-governmental organization representatives, and leaders of Community Based Organizations (CBOs) were considered as key informants and FGD participants. Accordingly, 12 KIIs, two mixed FGDs consisting of 20 people (12 men and eight women), and two PRA exercises were carried out with the same FGD participants. ${ }^{5}$

\section{Approaches to measuring vulnerability and resilience}

In terms of measurement, Deressa and Hassan (2009) documented the two commonly used approaches (i.e., econometric and indicator based) to measure vulnerability to disasters, including flooding. In the earlier case, the use of econometric method such as regression analysis is commonly employed to construct the Livelihood Vulnerability Index (hereafter referred to as LVI). The drawback of this technique is, however, the challenge associated with testing various econometric assumptions concerning the standard errors, hypotheses, confidence intervals and imputing causality without making stringent assumptions (Etwire et al., 2013). In the latter case, it involves the selection of indicators that the researcher finds to largely account for the vulnerability (Deressa and Hassan, 2009). In this approach, the subjectivity of the variable selection process is considered as a limitation (Etwire et al., 2013). Although this is a major limitation of the indicator based approach, recently different scholars used this approach to construct LVI in different contexts, including Ethiopia (Etwire et al., 2013; Limsakul et al., 2014; Madhuri et al., 2014; Simane et al., 2014). Similarly, this study adapted indicator based approach to develop LVI of smallholder farm households in the study district.

LVI developed by Hahn et al. (2009) was applied to assess the vulnerability of households in the study area.
The LVI measurement largely fits to the study context and target population (i.e., smallholder communities in sub Saharan Africa) and similar sample size based on primary data obtained through a cross-sectional survey. The LVI also helps to capture the key factors that reflect the vulnerability situation of smallholder farming communities in the face climate induced environmental hazards. Similar to the LVI used in Hahn et al. (2009), this study employed seven key variables, which relate to socio-demographic characteristics (SDC) (household size, dependency ratio, age, gender of household head and education), livelihood strategies (LS), health status (HS), food security status (FSS), access to water (AW), social network (SN), and flood disaster (FD) and its impact. Moreover, following Madhuri et al., (2014) and in line with the Sustainable Livelihood Framework (SLF) ${ }^{6}$ (Birkmann, 2006; Scoones, 2009) this study further included natural capital (NC) that mainly refers to ownership of land and size of farmland.

\section{Calculating the LVI}

The dimensions of vulnerability were systematically combined with equal weights to create an index on a scale of 0 to 1 . As in the case of the computation of the life expectancy index of the Human Development Index (HDI), the computation of each indicator of the vulnerability index followed the process of standardization (Hahn et al., 2009).

$$
I_{a}=\frac{S_{a}-S_{\min }}{S_{\max }-S_{\min }}
$$

Where, $I_{a}$ is the standardized value of each indicator. $S_{a}$ the original sub-component for household a, $S_{\min }$ is the minimum value of the indicator across all households, and $S_{\max }$ is the maximum value of the indicator across all households. After each indicator was standardized, the average value of each component was calculated using equation 2 :

$$
M_{a}=\frac{\sum_{a=1}^{n} I_{a^{i}}}{n}
$$

Where $M_{a}$ is the one of the eight components for household $a, I_{a^{i}}$ indicates the sub-components indexed by $i$, which builds each major component, and $n$ is the number of sub-components of each major component. After obtaining values for each of the eight components, the household level LVI was obtained by combining these components using equation 3 :

$$
L V I_{a}=\frac{\sum_{i=1}^{8} w_{M_{i}} M_{a^{i}}}{\sum_{i=1}^{8} w_{M_{i}}}
$$

Which can be further expressed as: 


$$
L V I_{a}=\frac{w_{S D C} S D C_{a}+w_{L S} L S_{a}+w_{H S} H S_{a}+w_{F S S} F S S_{a}+w_{A W} A W_{a}+w_{S N} S N_{a}+w_{F D} F D_{a}+w_{N C} N C_{a}}{w_{S D C}+w_{L S}+w_{H S}+w_{F S S}+w_{A W}+w_{S N}+w_{F D}+w_{N C}}
$$

Where $L V I_{a}$, is the Livelihood Vulnerability Index for household $a$, which equals the weighted average of eight major components, $w_{M_{i}}$. The weights of each major component are given by the number sub-component that make up each major component, which are used to guarantee that all sub-components have equal contribution to the total LVI (Sullivan, 2002; Hahn et al., 2009). The LVI value ranges between 0 and 1 , where 0 denotes the least vulnerable while 1 implies the most vulnerable (Etwire et al., 2013; Madhuri et al., 2014).

Resilience is a multidimensional concept that blends relevant evidence as to how people really withstand shocks (Almedom, 2009). Though the concept of resilience has been popular in development studies including, poverty, vulnerability, and food security, it has been challenging to find a sound measure to resilience and how to quantify resilience remains controversial (Alfani et al., 2015; Béné et al., 2016). However, some empirical studies have attempted to measure resilience using a composite index as proxy indicator (Amaya, 2014; Alfani et al., 2015; Alinovi et al., 2015; Béné et al., 2016; Smith et al., 2015). The current understanding of the resilience entails three interrelated capacities (adaptive, absorptive, and transformative), which are relevant to its measurement (Amaya, 2014; Frankenberger et al., 2014; Bahadur et al., 2015; Béné et al., 2016).

Resilience being a context-specific concept, the dimensions and indicators may change depending on the context. In assessing resilience to flood disasters, most studies use ex-post resilience indicators as opposed to $e x$ ante measurements partly because the debate in the resilience literature regarding the possibility of measuring resilience in the absence of a hazardous event is unsettled (Keating et al., 2014). Therefore, the SLF was adapted and built a resilience index using five capacity dimensions: social, economic, institutional, infrastructure, and community capacities with each having specific indicators. These indicators are then aggregated by equal weighting into the three components-adaptive, absorptive, and transformative capacitates to obtain a multidimensional livelihood resilience index (LRI), following similar steps used in the LVI computation as given by equations 1 to 4 (Amaya, 2014; Frankenberger et al., 2014; Suman, 2014; Smith et al., 2015). ${ }^{7}$ Thus, LRI constructed is expressed as:

$$
L R I_{a}=f\left(A C_{a}, A B C_{a}, T C_{a}\right)
$$

Where,

$L R I_{a}$ is the resilience index for household $a$
$A C_{a}$ is adaptive capacity for household $a$

$A B C_{a}$ is absorptive capacity for household $a$

$T C_{a}$ is transformative capacity for household $a$

Using the FAO's Resilience Index Measurement and Analysis (RIMA) model $^{8}$ (Food and Agricultural Organization [FAO], 2012; Alinovi et al., 2015) equation 5 can be further expressed as:

$$
L R I_{a}=f\left(I F A_{a}, A B S_{a}, A_{a}, S S N_{a}, S_{a}, A C_{a}\right)
$$

Where:

IFA refers to income and food access; $A B S=$ access to basic services;

$\mathrm{A}=$ assets; $\mathrm{SSN}$ = social safety nets; $\mathrm{S}=$ stability; $\mathrm{AC}=$ adaptive capacity. Since the indicators used in RIMA have been applied to measure household's resilience capacity to food insecurity (FAO, 2012; Alinovi et al., 2015), in this study, the RIMA components were contextualized and subsumed to into the three resilience capacity indicators to measure households' resilience to flood disasters. Accordingly, IFA, A, and AC indicators were taken as part of adaptive capacity along with other indicators; $\mathrm{S}$ was captured under absorptive capacity indicators using sensitivity to flood disasters as a proxy indictor in addition to others; and SSN and ABS were included under transformative capacity ${ }^{9}$.

As this index was a rough approximation of resilience and scale-sensitive, which may not be useful for interhousehold comparative analysis, a composite index using Principal Component Analysis (PCA) was constructed. PCA is a multivariate statistical technique mostly used for data reduction (i.e., larger number of variables into smaller numbers of components) and express the data as a set of new orthogonal variables called principal components (PCs) (Abdi and Williams, 2010; Abson et al., 2012; Schürer and Penkova, 2015). In this study, PCA was used both for data reduction and identification of the dominant factors that explain household's resilience to flood disasters.

There are number of ways that can be used to retain principal component score. In order to obtain PCs, the study used Kaiser criterion of extracting factors with eigenvalues greater than one, which is one of the frequently used technique (Abdi and Williams, 2010; Mooi and Sarstedt, 2011; Abson et al., 2012; Schürer and Penkova, 2015). Thus, the heaviest loading of principal component expressed in terms of the variables as an index for each household that captured largest amount of information (Abson et al., 2012). The individual 
resilience score using PCA was computed using equation 7 as follows:

$$
\begin{aligned}
R S_{a}= & f_{1} X\left(a_{a 1}-a_{1}\right) /\left(s_{1}\right)+\ldots \ldots \\
& +f_{N}\left(a_{a N}-a_{N}\right) /\left(s_{N}\right)
\end{aligned}
$$

Where $R S_{a}$ is the resilience score for household $a$;

$f_{1}$ is the component loading generated by PCA for the first variable;

$a_{a 1}$ is the $a^{\text {th }}$ household's value for the first variable;

$a_{1}$ and $s_{1}$ are the mean and standard deviation respectively of the first variable overall the households.

After extracting the principal components, a simple linear regression was applied to check the relationship between resilience and vulnerability as used in a similar study (Madhuri et al., 2014). Apart from this, following Nguyen and James (2013) a dichotomous response items were used to capture subjective indicators of household resilience to flooding. These indicators were quantified and integrated by using an exploratory factor analysis (Costello and Osborne, 2005; Child, 2006; Preacher et al., 2013). ${ }^{10}$

\section{Results and discussions}

\section{The nature of flooding and effects on livelihoods}

Natural hazards such as floods and droughts often expose poor communities to vulnerabilities that can be investigated from two dimensions (1) external dimensions or vulnerability context which can be expressed as the exposure to circumstances beyond people's control, including shocks, trends and seasonality (2) internal dimensions which refers mainly to socio-economic systems, access and use of resources to the extent to which peoples' livelihood is affected by the exposure to external factors (Blaikie et al., 2014; IFRCS, 2015).

In view of this therefore, the nature of flooding in the study area in terms of its cause, magnitude, severity, frequency and duration is discussed as a major component of the vulnerability context of people. Alongside this, by drawing together the findings from the household survey, the FGDs and the interviews with key informants on the effects of flooding on the livelihoods of people is discussed with the perceptions of people towards flooding as a livelihood threat.

Flooding in Dembia district is a seasonal phenomenon. The district is situated bordering the biggest lake in Ethiopia-Lake Tana. Several rivers that spring from neighboring districts drain into Lake Tana traversing the district. According to the information obtained from the district Disasters Prevention and Preparedness Desk, the major cause of flooding in the area can be attributed to the over-flow of five major rivers namely, Megech, Derema, Nededit, Gumara, and Senzelit during the rainy seasons. According to key informants, these rivers reach at peak flows in the main rainy season starting from July through August with water volume showing declines only in late September. As a result, the rivers regularly inundate many nearby villages with water staying on the plains for several weeks. However, some severe floods have occurred in the past that are associated with heavy rainfall in the highlands. For instance, the floods of 1995/96, 2001, and 2006 were mentioned by FGD participants as the most severe flood disasters. Secondary records obtained from DPPA corroborate this information and show that severe floods also occurred much earlier in 1973/74 and 1982/83 in the district (DPPC, 1997a).

A change in the severity of floods was also noted by experts and other study participants. People felt that flooding is more severe and frequent than in the past. Most of them came to understand that the population pressure and the associated farmland expansion have brought people close to the rivers which made them more vulnerable to flooding. This view partly agrees with the major assertion in the literature which relates to causes of people's vulnerability both to socio-economic and contextual factors compared to the mere exposure to floods (Handmer, 2003; Cannon, 2006).

In contrast, some participants stated that rivers have begun inundating farmlands and villages by changing their natural courses. For instance, one expert mentioned Megech River as one of such rivers that have changed its natural course since the 2006 flooding. The river (Megech) is now flowing in a new channel which is too narrow and shallow, causing the river to meander and spread out onto the plains easily overflowing its bank, flooding several villages in Tana Weyna Kebele.

Two points stand out from the above findings, (1) riverine flooding is the major type of flood in the study area (2) the nature of the flooding in the area is showing a marked change in terms of its severity having major consequences on the lives and livelihoods of people in the area. This finding is consistent with evidences from other studies in Ethiopia that suggest increasing frequency of flood hazards. In this regard, Maxwell et al. (2013) in their study of Tsaeda Amba district in Tigray (Northern Ethiopia) find that there is an increasing tendency of run-off and flooding due to environmental degradation. Similarly, a study by Tesso et al. (2012) indicates frequent flooding as a major environmental hazard that erode the coping capacities used by vulnerable communities such as kinship support network in North Shewa Zone of Oromia region. Focusing on riverine floods, a recent study by Hallegatte et al. (2016) that assessed the socioeconomic resilience to floods in 90 countries also found that, for poor people, a major risk associated with flood hazards is the loss of wellbeing. Other factors that contribute to and aggravate the flooding in the area were also revealed by FGDs and key 
informant interviews. The soil type of the district was mentioned as one such factor. According to informants from the district Agriculture and Rural Development Office, the black clay soil [which is the dominant soil type in the district] aggravates flooding as it is poor in its drainage capacity and gets saturated and sticky with even a small amount of rainfall. It also fails to absorb additional water flowing from rivers, contributing to flooding and water logging.

Although the nature of the watershed and soil type in the area can be mentioned as factors that influence the occurrence of flooding in the district, it is hardly possible to attribute the cause and the occurrence of flooding only to these factors. In fact, all of the district agricultural experts interviewed about the cause of flooding mentioned that flooding in the district is partly attributable to the following human activities that played a greater role in determining flood damage.

1. Deforestation: This made the highlands barren by exposing the top soil to heavy erosion and increasing the run-off of rain water from these areas to low areas. Periodic changes in the amount and intensity of rainfall aided by the lack of vegetation cover in the highlands also help in aggravating the run-off and the flooding in the study area.

2. Traditional and subsistence-oriented farming system in the highlands was mentioned as a factor that causes and accentuates the rate of soil erosion and run-off in the study area. According to the opinions of the district Agriculture and Rural Development experts, some irresponsible local farming practices such as tilling hilly lands have increased the problem of run-off and thereby contributed to increase flooding in low lying areas.

3. Lack of integrated conservation activities and watershed management was also mentioned as contributing factor to the rise in the frequency of flooding as well as the increasing human vulnerability in the area.

In general, the district's geographic location, topography and soil type aggravated by the effects of human intervention such as deforestation, traditional cultivation practices and lack of sustainable water-shed measures were found to cause or exacerbate flooding in the study villages.

\section{Effects of flood disaster on livelihoods}

Flooding has been affecting the study villages for years. According to the district agriculture and rural development office, the study villages experienced one of the worst floods in 2001 caused by the heavy rainfall in the highlands that increased the volume of Lake Tana and the tributary rivers sending huge amounts of water into the nearby plains and beyond. As a result, thousands have lost their assets and were dislocated from their homesteads. Flooding has shown an increase in its intensity in the flood prone villages since then particularly after the river Megech has changed its course and begun flowing in a shallow bank crossing major settlement areas, farm and grazing lands.

The findings from the household survey indicate that crop damage is most the common type of economic loss experienced by households in the study villages. Accordingly, nearly all surveyed households (98.3\%) reported that they have experienced loss of crops due to flooding in the last five years before the survey. Through the problem ranking and scoring exercises, participants of the FGDs also indicated that crop damage is the foremost impact of flooding in economic terms. The loss of standing crops such as teff was substantial during the floods in 2006 and 2009. During the FGDs in both villages, it was noted that farmers were compelled to change the cropping pattern from teff and wheat in to finger millet in recent years. In addition, almost all participants and key informants indicated that farmers in the study villages have begun to rely more on secondary crops such as chick-peas, field peas, and faba beans and other leguminous crops which grow by using the residual moisture left in the soil in the dry seasons. However, the overall production of cereals and pulses has gone down in recent years owing to the loss of soil fertility as a result of sedimentation which creates suffocation to such crops. In addition, the humidity of the soil resulting from flooding creates a favorable condition for pests such as Cut Worm (Agnotis Segetum) that reduces the productivity of the crops. In relation to this, one of the participants of FGDs in Tana Weyna Kebele disclosed that:

...flooding is making the cultivation of crops a challenging task. During the rainy season, it washes away crops that we grow spending so much labor and time and when we plant secondary crops, Korache [Cut-worm] destroys it.

The loss of primary crops and the declining productivity of secondary crops suggest that exposure to food insecurity is inevitable for the affected households. The effect of flooding on the food security of households is also amplified by the loss of production as a result of the time spent on recovery and rehabilitation in the aftermath of the flooding. Flooding has also increased the vulnerability of households to food insecurity as attested by the increasing relief grain requests made by the District Agricultural and Rural Development Office. 


\section{Households' vulnerability as measured in LVI}

The LVI that measures the vulnerability of households to flood disasters indicates that most households are highly vulnerable to flooding with a mean value being around 0.5. The LVI shows the inter-household differences in terms of exposure, sensitivity, and adaptive capacity. Accordingly, the major contributing factor to the high vulnerability of households to flooding in the study area is found to be exposure with a mean index value of 0.65 followed by sensitivity with a mean index value of 0.56 out of 1 (Fig. 2). Thus, most households are highly exposed to flooding and more sensitive to flood-related risks such as gully erosion resulting in the loss of both farm and pasture lands (see Fig. 3a). Studied households are also found to have relatively low adaptive capacity with a mean index of 0.53 out of 1 . This implies that the studied households have limited capacities in terms of offsetting flood disasters by employing long-lasting methods such as constructing flood dykes, which is only reported to have been used by 31.08 percent of households (see Table 3). Instead, as field observation shows many households largely rely on coping strategies mainly plastering the basement of their huts with daub, which may not help to withstand more severe flood hazards, frequenting the area in recent years (see Fig. 3b). Moreover, data from the household survey highlights that other frequently employed coping strategies include changing crops (86.01\%), relying on informal social transfers $(83.89 \%)$, and borrowing seeds $(80.93 \%)$ (see Table 3).

The results of qualitative interviews and discussions corroborated the findings from the LVI.

Accordingly, participants of FGDs mentioned that households with adequate labor can engage in dyke construction and timely drain their farmlands. Moreover, it was highlighted that such households are able to engage in both on-farm and off-farm activities and maintain their household income during times of extreme floods.

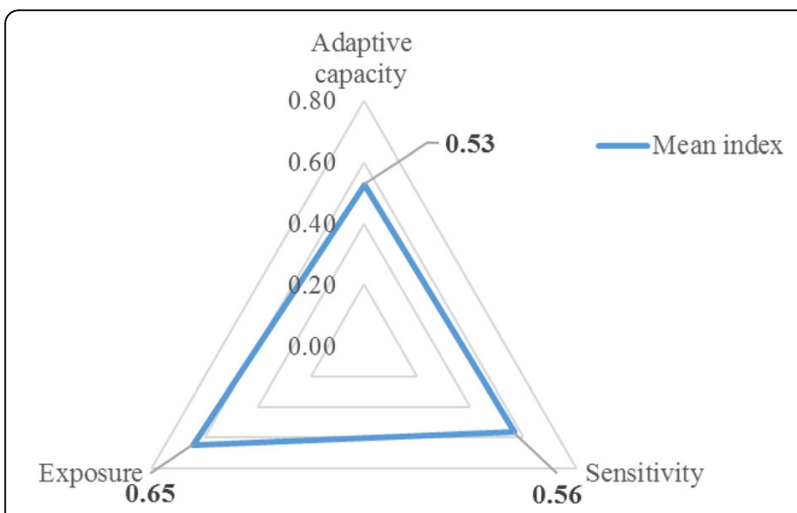

Fig. 2 The three components of vulnerability Source: Authors' own construction from household survey (April 2015)
However, the lack of access to alternative income earning activities in the district, coupled with the severity of the recent floods. These floods were mentioned to have adverse impacts on most farmers. Lack of human capital, particularly labor was reported to be a major factor that heightens households' vulnerability situation.

Focus group discussants agreed that the degree of exposure to flooding is mainly determined by the physical proximity of farmlands and settlement areas (villages). Poor asset holdings mainly farmlands and oxen were reported to be sources of social vulnerability. In the FGDs and KIIs, it was repeatedly noted that physical exposure to floods (physical vulnerability) was the major factor that puts studied households' livelihoods at risk. In view this, it was vividly indicated the "better-off" households in terms of asset holdings were highly affected by flood disaster, which resulted in to the loss of assets accumulated over time. The major floods that occurred in the 2006, 2008, and 2012 rainy seasons were mentioned as blatant examples of such phenomenon. This, however, does not mean that asset holding did not contribute to the resilience of households, it only confirms the fact that not all households in the study area were exposed to floods to the same extent and therefore were not affected in similar ways. This view strengthens the evidence that exposure to flood events is a necessary but not sufficient factor in determining the vulnerability of livelihoods. For instance, participants of FGDs in Tana Weyna Kebele, noted that the extent of flood damage on standing crops, depends more on the proximity of a farmland to the river Megech as opposed to the asset holding of the household. Accordingly, it was stated that households whose farmlands are located near to the river were exposed to more flood hazards both in the short and long rains.

To establish the relationship between the resilience and the vulnerability of households in the study area, Ordinary Least Square (OLS) regression was used with LVI as an explanatory variable and the resilience index obtained using PCA as a dependent variable.

The result shows that the LVI decreases livelihood resilience index by 6.73 points, statistically significant at less than $1 \%$. The first component of the PCA, which captures the largest variability of the sub-components is considered for capturing the resilience of surveyed households, which is composed of adaptive, absorptive, and transformative capacities (Frankenberger et al., 2014; Béné et al., 2016; Smith et al., 2015). The first component indicates the dominance of adaptive capacity over other components. The relationship between the two indices is to be expected as resilience is often taken to be the flip side of vulnerability (IPCC, 2001; 2007). In this study, adaptive capacity was taken as joint component shared between the LRI and LVI indices, however, 

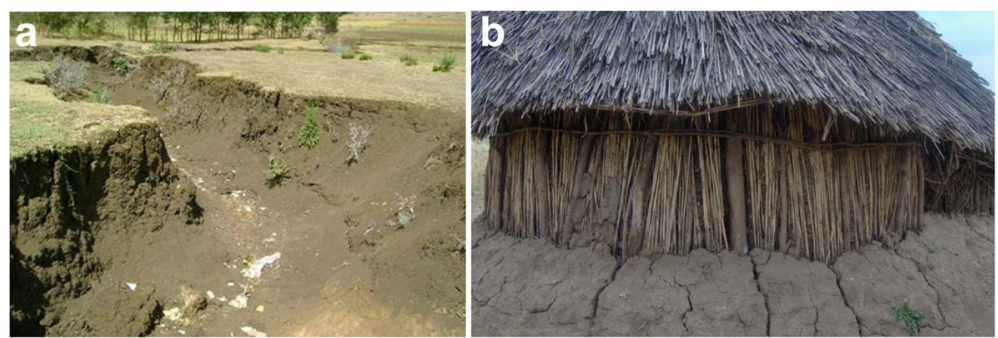

Fig. 3 a Gullies created by flooding. b House built with raised platform, plastered with mud to protect from floods. Source: Field observation in Debmia district (May 2015)

absorptive and transformative capacities as the other components of LRI that positively contribute towards households' overall resilience status seems to be relegated as the PCA only extracts the first componentadaptive capacity. Therefore, we argue that the comparison between the two indices need further analysis that captures the multidimensionality of both vulnerability and resilience.

\section{Households' resilience capacity as measured by LRI} Relying on PCA, factors that have eigenvalue greater than 1 were chosen as resilience indicators. Accordingly, the results from the PCA indicate that five of the 13 components have higher than one eigenvalues and represent $62.7 \%$ of the total variance (Table 4 and Fig. 4). Most of these variables belong to adaptive capacity indicators and include household and demographic characteristics (age, household size, education, and supply of labor). Next to household and demographic characteristics, livelihood diversification, which mainly belongs to absorptive capacity, describes the resilience of households towards flood disasters in the study area.

Following Nguyen and James (2013) those factor scores with the highest eigenvalue were used as a dependent variable for further analysis in the exploratory multiple regression. The result indicates that human and natural capital endowments mainly education and land holding size as well as engagement in more diversified activities mainly trade seems to be positive and

Table 3 Coping strategies for flood disasters

\begin{tabular}{llc}
\hline Coping strategy & Number & Percent \\
\hline Borrowing seeds & 236 & 80.93 \\
Selling household assets & 236 & 12.71 \\
Changing crops & 236 & 86.01 \\
Constructing flood dykes & 232 & 31.03 \\
Informal social transfers & 236 & 83.89 \\
Relocating to higher grounds & 234 & 58.97 \\
\hline
\end{tabular}

Source: Authors' own construction from household survey (April 2015) Note: This is a multiple response item and therefore the percentage does not add up to 100 percent. significant determinants of resilience of households (Table 5). Thus, those with higher educational levels and having relatively adequate farmlands are likely to have more resilience. Most importantly, engaging in trade as the highest form of diversified livelihood strategies is likely to increase LRI by 0.042 points, statistically significant at less than $1 \%$.

The factor analysis results on the dichotomous response items also show that three of the six statements express smallholders' subjective resilience. ${ }^{11}$ The first component represents $22.8 \%$ of the variance and relates to greater reliance on social networks that contributes to adaptive and absorptive capacities, for example in terms of borrowing seeds (Table 6). Here, crop damage being the most common type of economic loss experienced by households in the study villages reflects the crucial importance of social capital in a household's resilience.

At the time of disasters and soon after, people largely count on their kinship networks, mutual aid, self-help groups and indigenous organizations secure help and support (Haines et al., 1996; Aldrich, 2012). However, as the frequency and severity of co-variate shocks such as flooding increases, the role of social networks begins to wane. This process came out in the FGDs where participants have mentioned the severity of flooding in recent years as the main obstacle for relying less on kinship networks and neighbors. Moreover, flooding has affected the majority people in neighboring villages so much so that it was impossible to rely on kinship networks. For instance, one key informant explained that since the heavy flooding of 2006, the frequency and severity of

Table 4 Principal components of resilience indicators of households

\begin{tabular}{lclcc}
\hline Component & Eigenvalue & Difference & Proportion & Cumulative \\
\hline Comp1 & 2.68293 & .994965 & 0.2064 & 0.2064 \\
Comp2 & 1.68796 & .3136 & 0.1298 & 0.3362 \\
Comp3 & 1.37436 & .0426096 & 0.1057 & 0.4419 \\
Comp4 & 1.33175 & .258619 & 0.1024 & 0.5444 \\
Comp5 & 1.07313 & .0815582 & 0.0825 & 0.6269 \\
\hline
\end{tabular}

Source: Authors' own construction from household survey (April 2015) 


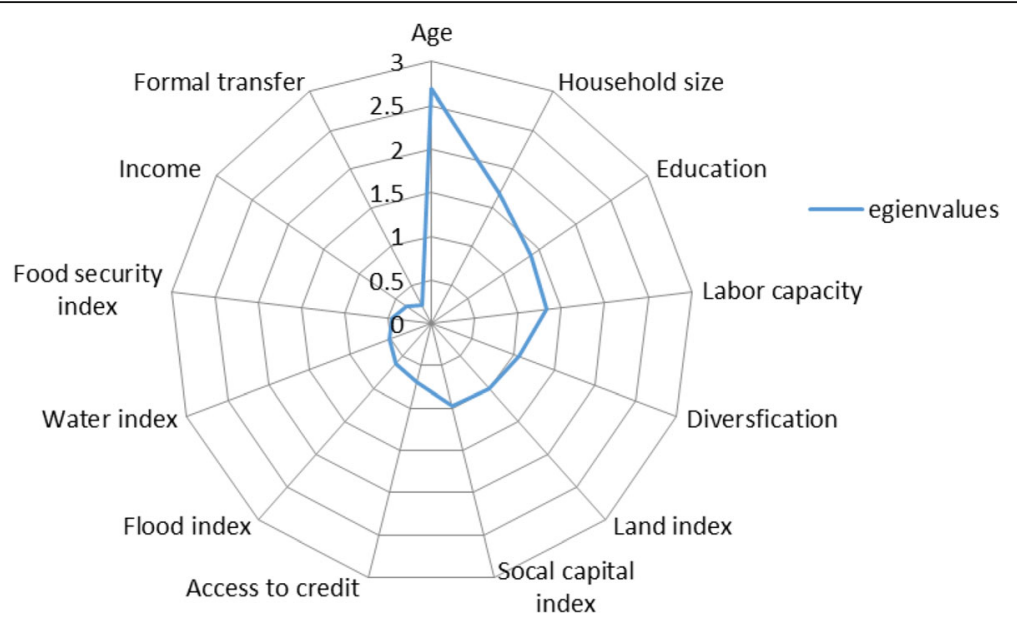

Fig. 4 Resilience spider diagram of the major components the LRI. Source: Authors' own construction from household survey (April 2015)

floods are increasing in all villages as a result of which households have to "rely on relief grains to sustain their lives". This opinion was also verified by data obtained from the District Agriculture and Development Office that showed an increase in relief grain recipients.

In general, resilience was understood as a state of having strength to quickly recover from the damages caused by flooding. A key component of livelihood resilience for many participants of FGDs and key informants was articulated as the ability to regain pre-disaster level of living without sustaining crippling damage to household assets that could push people further into poverty.

Moreover, during the focus group discussions it was indicated that flooding as a livelihood problem does not affect households equally in the study villages. This implies that the resilience of households is understood more in relative terms which further indicate the need to set some locally specific indicators in order to differentiate households in terms of their level of resilience. In this regard, the FGDs made with farmers in the study villages yielded some useful locally specific indicators that helped to measure the level of resilience of households.

Accordingly, the participants identified the location of farmland, critical asset holdings such as a pair of oxen, the ability to draw help form relatives in other villages, and time taken to recover from the impact of the floods as some of the major indictors of the livelihood resilience of households faced with flood- disasters in the study villages (Table 7). The categories were also used in the household survey to differentiate sample heads of households roughly in to three groups namely, those with high resilience, those with medium resilience and households with poor resilience or more vulnerable to flooding. These three categories only show the level of resilience of households in comparative terms and do not necessarily signify clear boundaries as they are only used to facilitate the analysis process. In addition, they do not show some causes of vulnerability such as illnesses, divorces and similar idiosyncratic shocks that contribute to the weakening of resilience.

Through FGDs and interviews, it was possible to identify major factors that limit the resilience and coping capacity of households in the face of flood disasters. Accordingly, participants and informants have identified a range of factors that determine the resilience of households, by focusing mainly on the major flood disasters that occurred in the study villages in the past ten years. Since the majority of factors relate with livelihood resources and access to them, attempt was made to assess the household livelihood situations by using a combination of qualitative and quantitative methods. Below, the major factors that determine the resilience of households are discussed.

\section{Natural capital: land}

In any rural community land is a basic productive resource, and access to it determines the wellbeing of a given livelihood. According to the findings of this study, however, farmland location, and fertility were indicated to be more important than a mere access to land in determining the resilience of households in the face of flood disasters. The FGDs and interviews made with the study households indicated that the qualities as well as the location of farmland are the key factors that limit or enhance the resilience of households to flood-induced shocks. In terms of location, the proximity of farmlands to rivers was mentioned to have a significant role in determining the vulnerability and resilience of households more than the size and fertility of farmlands. This finding was also supported by data obtained from the household survey, in which farmland ownership was not 
Table 5 Exploratory OLS on factors that determine LRI

\begin{tabular}{ll}
\hline Explanatory variables & \\
\hline Sex of household head & 0.00495 \\
Age of household head & $0.0128)$ \\
Educational status of household head & 0.000716 \\
& $(0.000569)$ \\
Household size & $0.00545^{*}$ \\
& $(0.00212)$ \\
Supply of labor & 0.00129 \\
Incidence of illness dummy & $(0.00429)$ \\
Land size in ha & 0.00657 \\
& $(0.00432)$ \\
Availability of farm oxen & -0.00180 \\
& $(0.0112)$ \\
Social networks & $0.0379^{* *}$ \\
Engagement in trade & $(0.0120)$ \\
Exposure to flood hazards & 0.0133 \\
& $(0.0133)$ \\
& 0.0321 \\
& $(0.0168)$ \\
& $0.0425^{* * *}$ \\
& $(0.0124)$ \\
& -0.0166 \\
& $(0.00996)$ \\
& $0.283^{* * *}$ \\
& $(0.0344)$ \\
& 214 \\
& 0.144 \\
\hline
\end{tabular}

Standard errors in parentheses

${ }^{*} p<0.05,{ }^{* *} p<0.01,{ }^{* * *} p<0.001$

Source: Authors' own construction from household survey (April 2015)

Notes:

The exploratory OLS model result has passed all the diagnostic tests such as multi-collinearity tests, omitted variables test, heteroscedasticity test and diagnostic plots to check the normality and linearity assumptions.

Table 6 Principal components/correlation of dichotomous response items

\begin{tabular}{lllcc}
\hline Component & Eigenvalue & Difference & Proportion & Cumulative \\
\hline Comp1 & 1.36742 & .30489 & 0.2279 & 0.2279 \\
Comp2 & 1.06253 & .054492 & 0.1771 & 0.4050 \\
Comp3 & 1.00804 & .086046 & 0.1680 & 0.5730 \\
Comp4 & .921993 & .048510 & 0.1537 & 0.7267 \\
Comp5 & .873483 & .106951 & 0.1456 & 0.8722 \\
Comp6 & .766532 &. & 0.1278 & 1.0000 \\
\hline
\end{tabular}

Source: Authors' own construction from household survey (April 2015) found to have a significant effect on the resilience of households as almost all of the households (92.8\%) own farmlands and those who do not own their own land were found to be equally distributed among the respondents.

This however cannot be taken to mean that access to land does not have a role in determining the resilience of households. In fact, it could be argued that access to land may indirectly determine resilience. The detailed discussions with participants of FGDs and key informants also indicated that farmers with no land holdings are less resilient to the effects of flooding as compared to those who have land or can access land through various mechanisms. This, as mentioned by focus group discussants and informants, was to be expected since the landless would lose their income largely drawn from wage labor on farms of other farmers during flooding and are likely to be affected even by moderate flooding as they lose the daily wages they earn from certain activities like weeding. Most participants of the FGDs also noted shortage of farmland in their respective villages. This problem, according to an informant from the Dwaro, have forced farmers, particularly the young ones to encroach the wetlands found on the shores of Lake Tana for planting horticultural crops such as spices. This finding corroborates with results from other studies that reported small landholdings, land degradation, and population pressure as the major causes of vulnerability to disasters in other parts of Ethiopia (Rahmato, 2007; Tesso et al., 2012; Maxwell et al., 2013).

\section{Economic capital: financial asset}

Economic capital generally refers to the financial resources that, in times of shocks could be used to reduce vulnerability and enhance recovery (Mayunga, 2007). The major forms of economic resource that were identified by the study households as having direct influence on the resilience or coping capacity of households are discussed as follows.

\section{Livestock holding}

Focus group discussants in the two study villages have identified the size and type of livestock owned by a household as a factor that determines the resilience of households. According to the focus group discussants, households who own a large number of livestock tend to be more resilient to the effects of flooding as they use the animals as a buffer stock. This gave them the financial capacity to quickly regain their livelihood, as they would sell their livestock and use the money to buy seeds, rent-in farmlands for planting secondary crops when the flood waters recede.

An interesting insight is also gained from the FGDs regarding the type of livestock and its role in the resilience 
Table 7 Factors that affect the resilience of households and communities in the face of flooding in the study villages

\begin{tabular}{|c|c|c|c|}
\hline Factors & Relatively resilient households & Households with Medium resilience & $\begin{array}{l}\text { Households with poor resilience / } \\
\text { more vulnerable households }\end{array}$ \\
\hline $\begin{array}{l}\text { Time to recover from the } \\
\text { impacts of major floods }\end{array}$ & $2-3$ months & 6 months & More than 6 months \\
\hline Size of farmland & 8-10 kada (2.0-2.5 ha) & 4-8 kada (1.0- 2 ha) & $\begin{array}{l}\text { Less than } 4 \text { kada ( } 1.0 \text { ha) but } \\
\text { mostly landless }\end{array}$ \\
\hline Livestock holding & $\begin{array}{l}\text { - Minimum } 4 \text { farm oxen - } 2 \text { cows } \\
\text { - } 2 \text { donkeys \& } 1 \text { or } 2 \text { mules }\end{array}$ & $\begin{array}{l}\text { - minimum } 2 \text { farm oxen } \\
-1 \text { or } 2 \text { cows } \\
-1 \text { donkey }\end{array}$ & $\begin{array}{l}\text { - } 1 \text { farm oxen or none } \\
\text { - no cows } \\
\text { - no pack animals }\end{array}$ \\
\hline Exposure to flooding & $\begin{array}{l}\text { Farm plots and homesteads } \\
\text { located far from river banks }\end{array}$ & $\begin{array}{l}\text { Farm plots and homesteads } \\
\text { located far from river banks }\end{array}$ & $\begin{array}{l}\text { Farm plots and homesteads } \\
\text { located near the river banks } \\
\text { or on the way where major } \\
\text { rivers usually break their banks }\end{array}$ \\
\hline $\begin{array}{l}\text { Availability of social } \\
\text { capital }\end{array}$ & $\begin{array}{l}\text { Have relatives in other districts or } \\
\text { villages and are able to send their } \\
\text { cattle to these places before the } \\
\text { coming to the rainy season on } \\
\text { regular basis. }\end{array}$ & $\begin{array}{l}\text { occasionally draw some help } \\
\text { from relatives in other villages } \\
\text { in the form of seeds or food } \\
\text { grains at times of flooding }\end{array}$ & $\begin{array}{l}\text { Largely depend on relief grains at } \\
\text { times of severe floods or resort to } \\
\text { taking loans from other households }\end{array}$ \\
\hline
\end{tabular}

Source: FGDs and key informant interviews (April 2015)

of the household. Accordingly, the participants of FGDs mentioned that possession of farm oxen often enhances the resilience of households, since it gives the advantage of draining flood water from farmlands so as to lessen crop damage or failure.

However, focus group discussion participants and key informants alike agreed that flooding, with increased volume of water and duration, affected livestock and reversed the situation in recent years, in which those with more livestock were affected the most, since they lost their livestock during the floods through drowning and in the aftermath through various diseases and lack of fodder, which in turn affected their productivity. In view of this one key informant said the following:

A decade ago, farmers in our village used to keep many cattle. In fact, some farmers used to own as much as 60 heads of cattle. Currently however we are having problems even to keep our farm oxen as the grazing fields are now covered with weeds and the cattle are starving as they no longer find those fine grasses that used to grow in the fields.

\section{Access to credit}

Access to credit services was the other form of financial capital, identified by household heads participated in the study, as having effect on the resilience of households.

According to the household survey 36.9 percent of the respondents were able to have access to credit. And out of these, only 24 percent of them were able to receive loans from formal rural credit services (Amhara Saving and Credit Institution[ASCI]). This indicates that there is lack of access to credit, which is crucial in helping households to quickly recover from the effects of floodinduced shocks to replace lost assets and income.
During the FGDs and interviews, it was also mentioned that households with no oxen, land and other assets were excluded from receiving loans as they were unable to furnish collateral. In relation to this, a young informant from Tana Weyna Kebele disclosed: "we are not given credit; they [ASCI] only give it to household heads who own land". This exacerbates their vulnerability to the effects of flood-induced shocks.

During the discussions, it was also indicated that those who have better access to credit were in a better position to withstand the aftermath shocks of flooding, as they can replace their lost assets. Participants of the FGD from the Gura Amba Kebele mentioned that there was good access to credit services as opposed to those in Tana Weyna Kebele. This difference in accessing credit could probably be explained by the differences in the degree of physical proximity to the main credit provider i.e. Amhara Saving and Credit Institution. Some informants from Tana Weyna Kebele have also asserted that credit service was not made available to farmers living in most villages as the staffs of ASCI avoid remote villages since there is a need to make frequent visits in attempting to ensure repayments.

Generally, it can be argued that those households with economic capital in the form of livestock and credit are in a better position to withstand and recover from the effects of flooding as such assets contribute to their resilience through creating more opportunities for livelihood diversification that enable households to manage and cope with flooding in more sustainable ways. Among those not having access to credit and economic assets, their resilience level is found to be very low. For instance, among the 130 households, who reported having no access to credit, only 9 (6.92 percent) were found to have LRI above 0.5 . Similarly, all the of the landless 
households were found to be non-resilient (see Additional file 1: Table B). These results indicate the important role that these and similar economic assets play in determining the resilience capacities of rural communities.

The FGD participants in both villages mentioned that more resilient households have the capacity to engage in both on-farm and off-farm diversification activities and keep a relatively good stock of animals in neighboring districts that enables them to further off-set livelihood shocks during major flood disasters like that of the 2006, 2008, and 2012 kremet floods. Diversification of income sources is stressed in the literature as an important strategy of enhancing the resilience of vulnerable communities and it "stands as the primary measure of household vulnerability and resilience (Tesso et al., 2012 p 884; Nguyen and James, 2013). Thus, given the benefits of diversification, households that diversify their income sources are likely to build their resilience to flood disasters in the future.

\section{Human capital}

Human capital as referring to the level of education, health conditions and availability of skilled labor was repeatedly mentioned as an important factor that shape the resilience of households and communities to disaster-induced shocks in the literature (Adger, 2000; Mayunga, 2007). In this study, the availability of labor in the household was found to be the most important form of human capital that contribute to household resilience in the face of recurring floods.

The qualitative data obtained from interviews and FGDs have also indicated that the availability of labor in a household play a determining role in enhancing the resilience of households. For instance, in explaining the role of labor in household livelihood resilience an informant in Gura Amba Kebele noted that "a farmer with no asset can live by the sweat of his brow as long as he is healthy and capable to work". This clearly shows the value of labor in in terms of determining the resilience capacity of households.

Table 8 provides a summary statistics of the responses of surveyed households with regards to exposure to flood hazards and loss of assets disaggregated by resilience status. As indicted in the Table, the resilient and non-resilient households provided more or less similar assessments on their loss due to flood hazards except for flood exposure. Further, looking at the educational status of households as one component of human capital that determines the resilience of households, the results from the survey showed that there the resilient groups are better than the non-resilient ones. However, this difference is not statistically significant as a two-sample $t$-test with equal variances gives a result of $\operatorname{Pr}(|\mathrm{T}|>|\mathrm{t}|)=$ 0.1455 . Thus, the evidences from the household survey seems to concur with the qualitative information that underlines the importance of the degree of exposure to flood hazards and the associated human activities such as land use changes. The finding on the prominent role of exposure concurs with Doocy et al. (2013) that provides a historical review of flood events worldwide from 1980 to 2009 and asserts that human vulnerability to floods is increasing among other things, mainly due to population growth, urbanization, and land use changes.

The major components of the LRI for the studied households is provided in Table 9. As shown in the Table, the mean LRI for all households is 0.44 , which is below the minimum threshold value-0.5. This indicates that most households are not resilient enough to in the face of the increasing flood hazards in the area. Moreover, from the sub-components of the LRI, one can see that the studied households seem to have relatively higher absorptive capacity than adaptive or transformative capacities, a further indication of their vulnerability.

With the view of providing a more illustrative representation of studied households' resilience capacity, we constructed a quadrant following the Andersen and Cardona (2013). The quadrant represents income per capita on the $\mathrm{x}$-axis and LRI on the y-axis. Households falling in the right side of the mean values include, rich, but not resilient groups, highly resilient, and extremely resilient groups (Fig. 5). Households in the left side of the threshold include, poor, but resilient, highly vulnerable, and extremely vulnerable groups. In terms of the

Table 8 Reported exposure to floods and loss of assets due to flooding

\begin{tabular}{ll}
\hline Resilient group & Non-resilient group \\
\hline Loss/damage to housing $63.41 \%(n=26)$ & Loss/damage to housing 69.66\% $(n=124)$ \\
Exposure to flood hazards $63.41 \%(n=26)$ & Exposure to flood hazards 56.74\% $(n=101)$ \\
Loss of crops due to flood hazards $95.12 \%(n=39)$ & Loss of crops due to flood hazards 99.44\% ( $n=177)$ \\
Loss of livestock due to flood hazards $73.17 \%(n=30)$ & Loss of livestock due to flood hazards 73.6\% $(n=131)$ \\
Ownership of at least an ox for farming 78.05\% (n=32) & Ownership of at least an ox for farming 79.78\% $(n=142)$ \\
Education (no. years of schooling) $3.43(n=41)$ & Education (no. years of schooling) 2.68 $(n=178)$ \\
\hline
\end{tabular}

Source: Authors' own construction from household survey (April 2015)

Notes:

Resilient and non-resilient groups were identified based on the LRI index values, where households having an LRI value of 0.5 and above were taken as resilient groups while those with LRI below this threshold were considered to non-resilient 
Table 9 Components of livelihood resilience index (LRI)

\begin{tabular}{lccccc}
\hline Variable & Obs. & Mean index & Std. Dev. & Min & Max \\
\hline Adaptive capacity & 222 & 0.55 & 0.07 & 0.17 & 0.73 \\
Absorptive capacity & 233 & 0.65 & 0.13 & 0.15 & 0.67 \\
Transformative capacity & 236 & 0.49 & 0.17 & 0.11 & 0.83 \\
LRI & 219 & 0.44 & 0.07 & 0.18 & 0.62 \\
\hline
\end{tabular}

Source: Authors' own construction from household survey (April 2015)

y-axis, the quadrant construction was based on the mean value of LRI, which was aggregated and/or composed from adaptive capacity index, absorptive capacity index, and transformative capacity index. The LRI value ranges between 0.1-0.99 (the lowest being 0.18 and the highest value stands at 0.62 ). The quadrant below and above the mean and/or threshold value divide was based on 0.44 LRI value. The quadrant with the mean value above 0.44 consists of poor but resilient, highly resilient, and extremely resilient groups. While, the quadrant with the mean value below the mean includes, rich but not resilient, highly vulnerable, and extremely vulnerable groups. The average monthly income of households is about 10.26 USD, which reflects the level of poverty and depravation among the study communities as this would mean that the average daily income of households is only 0.34 USD. As can be shown from Fig. 5, even by taking this low income level as a threshold, $31.9 \%$ of households were found to be vulnerable. When roughly extrapolated to the district level using CSA (2013) figures, this proportion would mean that 88,417 people are vulnerable to flood hazards in the district out of the 277,170-rural population.
The above quadrant is informative in terms of offering data as to where to focus development intervention efforts. In this regard, it is imperative to invest on various livelihood resilience schemes that enhances the capacity of highly and extremely resilient groups while focusing on reducing the number of highly and extremely vulnerable groups. Apart from this, it is also important to work on empowering poor-but resilient households and rich but not resilience households. This is particularly important given the overwhelming evidence, which indicates the likelihood of a shift in the global pattern and intensity of flood hazards associated with climate change (Few, 2003).

\section{Conclusions}

Focusing mainly on the vulnerability and resilience of rural households in one of the flood prone areas in Ethiopia- Dembia district, the study attempted to show that the nature of flooding in the study area has markedly changed over the past decade. The floods have become more frequent and severe owing to a number of factors that derive from both climatic and topographic conditions such as, periodic changes in the amount of rainfall, the nature of watershed system and soil type of the area. In addition, certain human activities including deforestation, increased settlement on flood plains, and traditional systems of cultivation were found to aggravate flood hazards in the area.

The findings of the study highlight the importance of access and use of livelihood resources such as size of farmlands, access to income diversifying options, credit as well as ability to draw help from social networks in terms of determining the resilience of households facing

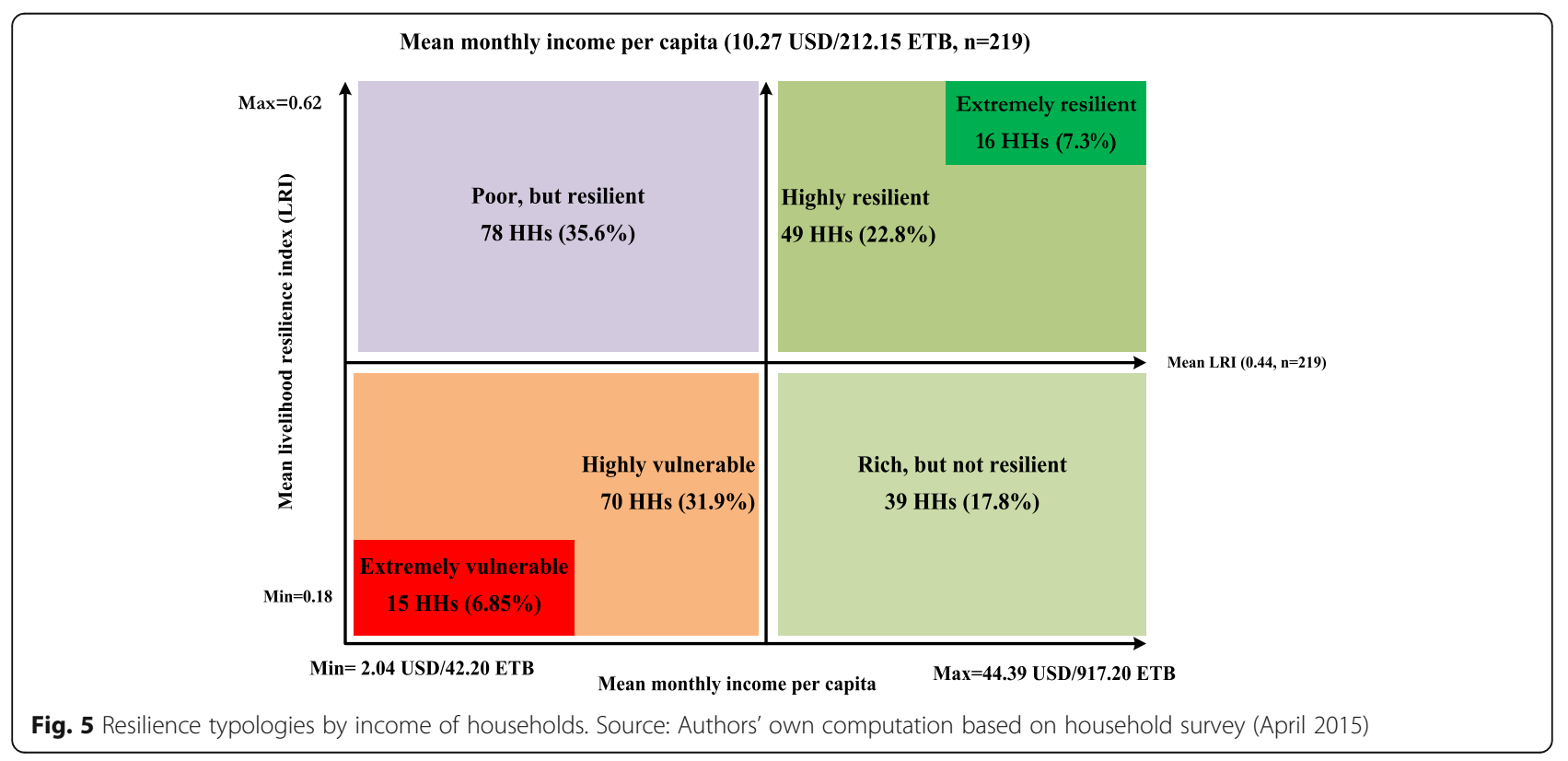


frequent flood hazards. The scale and impact of the recent floods and lack of basic infrastructural and social facilities are also found to have hampered the use of robust coping strategies by affected communities and households.

Given the livelihood context of smallholder farming system in the studied area, which is highly vulnerable to environmental hazards and persistently challenged by population pressure and land degradation, it is highly likely that the size of farm land will remain to be a major determining factor of the resilience capacity of the studied households. Despite this, however, context specific institutional interventions such as the integrated use of both safety nets and cargo nets may off-set livelihood predicaments. The safety nets can be implemented in the form of public works that are relevant to minimizing exposure to the recurring flood hazards, particularly through construction and maintenance of flood dykes. The cargo nets can be put in place in the form of targeted microfinance, flood insurance schemes, or agricultural input subsidization. These interventions will strengthen both the absorptive and adaptive capacities of households and communities in the short-term while enhancing their transformative capacity in the longterm. These imply that policy should focus more on addressing the factors that expose people to flood disasters and shape their resilience, rather than focusing on short-term emergency responses, which seems to be the norm in much of the flood affected areas in Ethiopia.

\section{Endnotes}

${ }^{1}$ Resilience as a concept has been highly promoted as a uniting policy instrument that links humanitarian and development approaches to address peoples' chronic vulnerability to recurrent shocks and disasters (Choularton et al., 2015). These view is also shared by the Sendai Framework for Disaster Risk Reduction (UN, 2015a) and the UN's Paris Agreement on Framework Convention on Climate Change (UN, 2015b).

${ }^{2}$ Kebele is the lowest administrative unit in Ethiopia.

${ }^{3}$ These criteria were used to account for variations in the degree of flood-hazard exposure as all of the eight Kebeles are not equally affected by the flood disasters. Hence, the two Kebeles were selected out of the eight Kebeles to ensure the representativeness of the sample drawn from the Kebeles.

${ }^{4}$ The overall sample size was determined by using the sample size determination equation that takes into account the desired confidence level (95\%), the error margin (5\%), and the prevalence of the issue under investigation $(p=0.5)$. The required sample size was determined using Kothari (2004) sample size determination formula. 28 households did not respond the major modules of the structured household survey and were considered as non-response cases $(9.8 \%$ of the total sample size).

${ }^{5}$ The size of a sample in purposive sampling is often determined on the basis of "theoretical saturation" (the point in data collection when new data no longer provide additional insights to the research questions) (May, 2002; Patton, 2002).

${ }^{6}$ The concern of livelihood approach is to understand how different in different places live (Scoones, 2009). Apart from being an analytical tool, SLF takes vulnerability as a comprehensive concept covering livelihood assets and their access, and vulnerability context elements (i.e., shocks, seasonality, and trends) as well as institutional structure and processes (Birkmann, 2006).

${ }^{7}$ To capture adaptive capacity, we used labor, education, asset (income)/consumption/per capita, household size, natural capital, and social capital. Absorptive capacity is captured through access to credit, asset, diversification, flood disaster exposure indices. The transformative capacity is measured by using access to services, infrastructure, and formal safety nets.

${ }^{8}$ Very recently, FAO proposed RIMA-II, which is an indirect measure of resilience that adopts regression analysis allowing for making causal inference. However, RIMA-II is more suitable for assessing the dynamic nature of household resilience to measurable outcomes such as food insecurity, which requires the use of panel data.

${ }^{9}$ Adaptive capacity (AC) indicators include: IFA (income and consumption per capita), A (availability of labor, ownership of asset, and natural capital (land)), AC (educational status). Other indicators included are: social capital (informal transfers and participation in festive work groups) and household size; Absorptive capacity $(\mathrm{ABC})$ indicators include, S Access to credit, asset ownership, diversification of income, and flood index (flood duration, flood severity, exposure to flood disasters, frequency of flood disasters, and losses sustained due to flood disasters including crops, damage to housing, and loss of livestock); and Transformative capacity (TC) indicators include, SSN (access to formal safety net (Productive Safety Net Program)) and ABS (access to services, access to infrastructure).

${ }^{10}$ There are two major types of factor analysis techniques (These are namely, Confirmatory Factor Analysis (CFA) and Exploratory Factor Analysis (EFA). The former CFA helps to check hypotheses and uses path analysis diagrams to denote variables and factors. The latter, EFA attempts to discover multifaceted patterns by exploring the dataset and testing predictions (Costello and Osborne, 2005; Child, 2006). As for the rotation techniques. There are two types, viz, orthogonal rotation and oblique rotation. The first, orthogonal rotation (e.g.,Varimax and Quartimax) consists of uncorrelated factors whereas oblique rotation (e.g., Direct Oblimin and Promax) includes correlated factors. The interpretation of factor 
analysis is based on rotated factor loadings, rotated eigenvalues, and scree test. In reality, researchers often apply more than one extraction and rotation technique relying on pragmatic reasoning rather than theoretical reasoning (Preacher et al., 2013). Thus, for the sake of brevity in interpretation, this study used varimax method of rotation variables that helps to reduce the number of variables with a high loading on a factor.

${ }^{11}$ Owing to the complex nature of the concept and the lack of an exact equivalent of the word resilience in the local Amharic dialect, it was necessary to first obtain farmers own subjective meanings of the term through group discussions. Accordingly, the participants of FGDs in both villages, agreed that the concept has a positive connotation in the sense that it matched with certain terms like 'ability,' 'capacity', 'strength' and 'resistance'.

\section{Additional file}

Additional file 1: Statistics on the incidence and effects of major natura disasters. (DOC $314 \mathrm{~kb}$ )

\section{Acknowledgements}

We would like to thank the study participants for volunteering information on which this study is based. The constructive comments from two reviewers are sincerely acknowledged.

\section{Authors' contributions}

The corresponding author, ZBW is an Assistant Professor of Development Studies at the Center for African and Oriental Studies (CAfOS), Addis Ababa University. He designed the data collecting instruments, performed the statistical analysis, and drafted the manuscript. BEA is a PhD candidate at the Center for Environment and Development, Addis Ababa University. He participated in reviewing pertinent literature, collecting the data, performing statistical analysis, and drafting the manuscript. Both authors contributed to and approved the final manuscript.

\section{Competing interests}

The authors declare that they have no competing interests.

\section{Author details}

${ }^{1}$ Center for African and Oriental Studies, Addis Ababa University, P.O. Box: 1176, Addis Ababa, Ethiopia. ${ }^{2}$ Center for Environment and Development, Addis Ababa University, P.O. Box: 1176 Addis Ababa, Ethiopia.

Received: 21 July 2016 Accepted: 24 February 2017

Published online: 09 March 2017

\section{References}

Abdi, H., and L.J. Williams. 2010. Principal component analysis. Wiley Interdiscip Rev Comput Stat 2: 433-459.

Abson, D.J., A.J. Dougill, and L.C. Stringer. 2012. Using principal component analysis for information-rich socio-ecological vulnerability mapping in Southern Africa. Applied Geography: 1-10. doi:10.1016/j.apgeog.2012.08.004.

Adger, W.N. 2000. Social and ecological resilience: are they related? Progress in Human Geography 24(3): 347-364.

Adger, W.N. 2006. Vulnerability. Global Environmental Change 16: 268-281. doi:10. 1016/j.gloenvcha.2006.02.006.

Aldrich, D. P. 2012. Building Resilience: Social Capital in Post Disaster Recovery. Chicago: University of Chicago Press.

Alfani, F., A. Dabalen, P. Fisker, and V. Molini. 2015. Can we measure resilience? a proposed method and evidence from countries in the Sahel. A Proposed Method and Evidence from Countries in the Sahel, World Bank Policy Research Working Paper, 7170.
Alinovi, L, E. Mane, and D. Romano. 2009. Towards the measurement of household resilience to food insecurity: An application to Palestinian households. European Commission and the United Nations Food \& Agriculture Organization Working Paper. Available at http://www.fsnnetwork.org/sites/default/files/ measuring_household_resilience_to_food_insecurity.pdf. Accessed $20 \mathrm{Nov}$ 2015.

Almedom, A.M. 2009. A call for resilience index for health and social system in Africa. Issues in Brief. The Federick S Pardee Center for the study of the Longer-Range Future. Number 10, October 2010. Retrieved from http://www. bu.edu/pardee/policy-010-resilience-index/.

Amaya, L.C. 2014. Disaster resilience to food insecurity metrics: A case study in rural Costa Rica. PhD Dissertation. USA: Texas State University.

Andersen, L.E., and M. Cardona. 2013. Building Resilience against adverse shocks: What are the determinants of vulnerability and resilience? Development Research Working Paper Series, 2.

Bahadur, A., E. Lovell, E. Wilkinson, and T. Tanner. 2015. Resilience in SGDs: Developing Indicators for target 1.5 that is fit for the purpose, Briefing Paper, 1-6. London: Oversee Development Institute.

Bekele, L. 2003. Community perceptions and responses to Awash Floods in the Wonji environs, Ethiopia. Ethiopian Journal of Development Research 25(2): 1-33.

Béné, C., D. Headey, L. Haddad, and K. von Grebmer. 2016. Is resilience a useful concept in the context of food security and nutrition programs? Some conceptual and practical considerations. Food Security 8(1):123-138.

Berhanu, W., and B. Fekadu. 2015. Climate variability and household adaptation strategies in Southern Ethiopia. Sustainability 7: 6353-6375.

Birkmann, J. 2006. Measuring vulnerability to promote disaster-resilient societies: Conceptual frameworks and definitions. Measuring vulnerability to natural hazards 1: 9-54.

Blaikie, P., T. Cannon, I. Davis, and B. Wisner. 2014. At risk: natural hazards, people's vulnerability and disasters. London: Routledge.

Cannon, T. 2006. Vulnerability analysis, livelihoods and disasters. Risk 21: 41-49.

Central Statistics Authority (CSA). 2007. Summary and statistical report of population and housing census: Population size by age and sex. Addis Ababa: Federal Democratic Republic of Ethiopia (FDRE).

Central Statistics Authority (CSA). 2013. Federal Democratic Republic of Ethiopia (FDRE). Population projection of Ethiopia for all regions: At Wereda level from 2014-2017. Addis Ababa: Federal Democratic Republic of Ethiopia (FDRE).

Child, D. 2006. The essentials of factor analysis, 3rd ed. New York: Continuum International Publishing Group.

Choularton, R., T. Frankenberger, J. Kurtz, and S. Nelson. 2015. Measuring shocks and stressors as part of resilience measurement, Resilience Measurement Technical Working Group. Technical Series, 5.

Constas, M., and C. Barrett. 2013. Principles of resilience measurement for food insecurity: metrics, mechanisms, and implementation plans, Paper presented at Expert Consultation on Resilience Measurement Related to Food Security, Rome.

Costello, A.B., and J.W. Osborne. 2005. Best practices in exploratory factor analysis: Four recommendations for getting the most from your analysis. Practical Assessment Research and Evaluation 10(7): 1-9.

Cutter, S. L. 2016. Resilience to what? Resilience for whom? The Geographical Journal, n/a-n/a. http://doi.org/10.1111/geoj.12174.

Deressa, T.T., and R. M. Hassan. 2009. Economic impact of climate change on crop production in Ethiopia: evidence from cross-section measures. Journal of African Economies 18(4): 529-554.

Deressa, T., R. Hassan, and C. Ringler. 2008. Measuring Ethiopian farmers' vulnerability to climate change Across Regional States. In International Food Policy Research Institute (IFPRI) Discussion Paper 00806.

Disaster Prevention and Preparedness Agency. (DPPA). 2007. Regional summary of multi-agency flood impact assessment of 2006. Addis Ababa: Early Warning Department.

Disaster Prevention and Preparedness Commission. 1997b. Worst case scenario for drought, flood, influx of refugees and epidemics and the present response system. June 1997: Addis Ababa: Federal Democratic Republic of Ethiopia (FDRE).

Disaster Prevention and Preparedness Commission (DPPC). 1994. Non-drought disaster propensity in Ethiopia. Final report April, 1994. Addis Ababa: Federal Democratic Republic of Ethiopia (FDRE).

Disaster Prevention and Preparedness Commission. (DPPC). 1997a. Flood vulnerability in Ethiopia and needs for preparedness. June, 1997: Addis Ababa: Federal Democratic Republic of Ethiopia (FDRE). 
Doocy, S., A. Daniels, S. Murray, and T.D. Kirsch. 2013. The human impact of floods: A historical review of events 1980-2009 and systematic literature review. PLOS Currents Disasters 5(1). doi:10.1371/currents.dis.f4deb457904936b07c09daa98ee8171a.

Engle, N.L. 2011. Adaptive capacity and its assessment. Global Environmental Change 21: 647-656.

Ethiopian Panel of Climate Change (EPCC). 2015. First Assessment Report. In Working Group II Agriculture and Food Security. Addis Ababa: Ethiopian Academy of Sciences.

Etwire, P.M., R.M. Al-Hassan, J.K.M. Kuwornu, and Y. Osei-Owusu. 2013. Application of livelihood vulnerability index in assessing vulnerability to climate change and variability in Northern Ghana. Journal of Environment and Earth Science 3(2): 157-170.

Few, R. 2003. Flooding, Vulnerability and coping strategies: local responses to a global threat. Progress in Development Studies 3(1): 43-58.

Food and Agricultural Organization (FAO). 2012. Measuring resilience: A concept note on the resilience tool. Rome: The United Nations Food and Agricultural Organization. Available at http://www.fao.org/resilience/resources/resourcesdetail/en/c/317275/.

Frankenberger, T., and S. Nelson. 2013. Background paper for the expert consultation on resilience measurement for food security. In Paper presented at Expert Consultation on Resilience Measurement Related to Food Security, Rome.

Frankenberger, T., T. Spangler, S. Nelson, and M. Langworthy. 2012. Enhancing resilience to food security shocks in Africa. In Discussion Paper.

Frankenberger, T.R., M.A. Constas, S. Nelson, and L. Starr. 2014. Current approaches to resilience programming among Non-Governmental Organizations. In 2020 Conference Paper, vol. 7, 1-42.

Guha-Sapir, D., P. Hoyois, and R. Below. 2015. Annual Disaster Statistical Review 2014: The numbers and trends. Centre for Research on the Epidemiology of Disasters (CRED). (http://reliefweb.int/report/world/annual-disaster-statisticalreview-2014-numbers-and-trends). Accessed 5 Feb 2016.

Hahn, M.B., A.M. Riederer, and S.O. Foster. 2009. The livelihood vulnerability index: A pragmatic approach to assessing risks from climate variability and change-A case study in Mozambique. Global Environmental Change 19(1): 74-88.

Haines, V. A., J.S. Hurlbert, and J.J. Beggs. 1996. Exploring the determinants of support provision: Provider characteristics, personal networks, community contexts, and support following life events. Journal of Health and Social Behavior 37(3):252-264.

Hallegatte, S., M. Bangalore, and A. Vogt-Schilb. 2016. Assessing socioeconomic resilience to floods in 90 countries. In World Bank Policy Research Working Paper 7663. Washington DC: World Bank Group.

Handmer, J. 2003. We are all vulnerable. Australian Journal of Emergency Management 18: 55-60.

Hirabayashi, Y., R. Mahendran, S. Koirala, L. Konoshima, D. Yamazaki, S. Watanabe, and S. Kanae. 2013. Global flood risk under climate change. Nature Climate Change 3(9): 816-821.

Hoddinott, J. 2014. Understanding resilience for food and nutrition security. 2020 Conference Paper 8. Addis Ababa: International Food Policy Research Institute (IFPRI).

Intergovernmental Panel on Climate Change (IPCC). 2001. Climate Change 2001: The Scientific Basis. IPCC Third Assessment Report.

Intergovernmental Panel on Climate Change (IPCC). 2007. Climate Change 2007. Impacts, adaptation and vulnerability: Working Group II contribution to the Fourth Assessment Report of the Intergovernmental Panel on Climate Change (IPCC). Cambridge: Cambridge University Press.

Intergovernmental Panel on Climate Change (IPCC). 2012. Managing the Risks of extreme events and disasters to advance climate change adaptation. Cambridge: Cambridge University Press.

Intergovernmental Panel on Climate Change (IPCC). 2014. Climate Change 2014. Mitigation of climate change. Contribution of Working Group III to the Fifth Assessment Report of the Intergovernmental Panel on Climate Change. Cambridge, UK: Cambridge University Press.

International Federation of Red Cross and Red Crescent Societies (IFRCS). 2015. World Disasters Report 2015: Focus on local actors, the key to humanitarian effectiveness. Geneva: International Federation of Red Cross and Red Crescent Societies. Available at https://ifrc-media.org/interactive/wp-content/ uploads/2015/09/1293600-World-Disasters-Report-2015_en.pdf. Accessed 10 Feb 2016.

Jongman, B., S. Hochrainer-Stigler, L. Feyen, J.C. Aerts, R. Mechler, W.W. Botzen, and P.J. Ward. 2014. Increasing stress on disaster-risk finance due to large floods. Nature Climate Change 4(4): 264-268.
Keating, A., K. Campbell, R. Mechler, E. Michel-Kerjan, J. Mochizuki, and C. Egan. 2014. Operationalizing resilience against natural disaster risk: opportunities, barriers and a way forward.

Kothari, C.R. 2004. Research methodology: methods and techniques, 2nd ed. New Delhi: New Age International Publisher Ltd.

Kreft, S., D. Eckstein, L. Dorsch, and L. Fischer. 2016. Global Climate Risk Index 2016. Who suffers most from extreme weather events? Weather-related Loss events in 2014 and 1995 to 2014. Briefing Paper, 1-32. Germany: Germanwatch e.V. Bonn.

Limsakul, A., W. Katasaenee, W. Paengkaew, A. Kammuang, D. Tipmanee, and P. Sompongchaiyakul. 2014. Vulnerability index to climate change and its application for community-level risk assessment in Thailand. Environment Asia 7(2): 108-116.

Madhuri, H.R. Tewari, and P.K. Bhowmick. 2014. Livelihood vulnerability index analysis: an approach to study vulnerability in the context of Bihar: original research, Jamba. Journal of Disaster Risk Studies 6(1): 1-13.

Maru, Y. T., S.M. Stafford, A. Sparrow, P.F. Pinho, and O.P. Dube. 2014. A linked vulnerability and resilience framework for adaptation pathways in remote disadvantaged communities. Global Environmental Change. doi:10.1016/j. gloenvcha.2013.12.007.

Maxwell, D., B. Vaitla, G. Tesfay, and N. Abadi. 2013. Resilience, food security dynamics, and poverty traps in Northern Ethiopia, Analysis of a Biannual Panel Dataset, 2011-2013. Medford: Feinstein International Center, Tufts University.

May, T. 2002. Qualitative research in action. London: Sage Publications.

Mayunga, S.J. 2007. Understanding and applying the concept of community disaster resilience: A capital-based approach: a draft working Paper prepared for the summer academy for social vulnerability and resilience building, 22-28 July 2007, Munich, Germany.

Mengistu, A., A. Argaw, and T. Seid. 2015. Resilience of Ecosystems to climate change. American Journal of Environmental Protection 4(6): 325-333.

Moges, A .1978. Flood risks and vulnerability in different regions of Ethiopia. Disaster Preparedness Planning Program. Relief and Rehabilitation Commission. Addis Ababa: Relief and Rehabilitation Commission (RRC).

Mooi, E., and M. Sarstedt. 2011. A concise guide to market research: The process, data, and methods using IBM SPSS Statistics. Heidelberg: Springer.

Munich RE. 2015. Loss events worldwide 1980-2014 (1-10). Munich: Munich RE.

Nederveen, S., M. Abebe, F.V. Steenbergen, A. Tena, and G. Yohannes. 2011. Flood based farming practices in Ethiopia: status and potential, Overview Paper Spate Irrigation 3.

Nguyen, K., and H. James. 2013. Measuring household resilience to floods: A case study in the Vietnamese Mekong River Delta. Ecology and Society 18(3):13. http://www.ecologyandsociety.org/vol18/iss3/art13/.

Patton, M.Q. 2002. Qualitative research and evaluation methods ( $3^{\text {rd }}$ ed.). Thousand Oaks: Sage.

Preacher, K.., G. Zhang, C. Kim, and G. Mels. 2013. Choosing the optimal number of factors in exploratory factor analysis: A model selection perspective. Multivariate Behavioral Research 48(1): 28-56.

Rahmato, D. 1991. Famine and survival strategies: a case study from Northeast Ethiopia. Nordic Africa Institute.

Rahmato, D. 2007. Development intervention in Wollaita, 1960s-2000s: a critical review. Forum for social studies monograph 4. Addis Ababa: Forum for Social Studies.

Razafindrabe, B., M.B. Cuesta, R. He, K. Rañola Jr., S. Yaota, Inoue, and A. Santos-Borja. 2015. Flood risk and resilience assessment for Santa Rosa-Silang sub-watershed in the Laguna Lake region, Philippines. Environmental Hazards 14(1): 16-35.

Sallu, S.M., C. Twyman, and L.C. Stringer. 2010. Resilient or vulnerable livelihoods? Assessing livelihood dynamics and trajectories in rural Botswana. Ecology and Society 15(4): 1-24.

Savage, M., A. Mujica, F. Chiappe, and I. Ross. 2015. Climate finance and water security: Ethiopia case study. Oxford Policy Management (OPM) Client Report: 1-30. June 2015. Available at http://www.opml.co.uk/publications/climatefinance-and-watersecurity-ethiopia-case-study.

Schürer, K., and T. Penkova. 2015. Creating a typology of parishes in England and Wales: Mining 1881 census data. Historical Life Course Studies 2: 38-57.

Scoones, I. 2009. Livelihoods perspectives and rural development. The Journal of Peasant Studies 36(1): 171-196.

Sharp, K., S. DevereuX, and Y. Amare. 2003. Destitution in Ethiopia's Northeastern highlands (Amhara National Regional State). In Institute of Development Studies at the University of Sussex.

Simane, B., B.F. Zaitchik, and J.D. Foltz. 2014. Agroecosystem specific climate vulnerability analysis: application of the livelihood vulnerability index to a 
tropical highland region. Mitigation and Adaptation Strategies for Global Change 21(1): 39-65.

Smith, L., T. Frankenberger, B. Langworthy, S. Martin, T. Spangler, S. Nelson, and J. Downen. 2015. Ethiopia Pastoralist areas resilience improvement and market expansion (PRIME) Project Impact Evaluation. In Baseline Survey Report Vol. 1, U.S. Agency for International Development, Feed the Future Feedback, 1-155.

Sullivan, C. 2002. Calculating a water poverty index. World Development 30: 1195-1210. doi:10.1016/50305-750X(02)00035-9.

Suman, S.L. 2014. Climate change resilience and vulnerability of farmers in Nepal. Doctoral Dissertation. Japan: Hiroshima University.

Tanner, T., D. Lewis, D. Wrathall, R. Bronen, N. Cradock-Henry, S. Huq, and M.A. Rahman. 2015. Livelihood resilience in the face of climate change. Nature Climate Change 5(1): 23-26.

Tesso, G., B. Emana, and M. Ketema. 2012. Analysis of vulnerability and resilience to climate change induced shocks in North Shewa, Ethiopia. Agricultural Sciences 3: 871-888

United Nations (UN). 2015a. Sendai Framework for Disaster Risk Reduction 2015-2030 (http://www.unisdr.org/we/coordinate/sendai-framework). Accessed 3 Mar 2016.

United Nations (UN). 2015b. Adoption of the Paris Agreement. UNFCCC. Report No. FCCC/CP/2015/L.9/Rev.1, (http://unfccc.int/resource/docs/2015/cop21/eng/ 109r01.pdf). Accessed 3 Mar 2016.

United Nations (UN). 2015c. Sustainable Development Goals (http://www.un. org/sustainabledevelopment/sustainable-development-goals/). Accessed 3 Mar 2016.

United Nations International strategy for Disaster Reduction (UNISDR). 2015. Global Assessment Report on Disaster Risk Reduction.

United Nations Office for the Coordination of Humanitarian Affairs (UN-OCHA). 2016. Humanitarian funding analysis: Flood and impacts in Ethiopia. In UN Office for the Coordination of Humanitarian Affairs, Crisis Briefing.

United Nations Office for the Coordination of Humanitarian Affairs. (UN-OCHA). 2006. Situation Report on floods in Ethiopia.No.3 21st August 2006.

Woldemariam, M. 1986. Rural vulnerability to famine in Ethiopia, 1958-1977. New Delhi: Vikas publishing House LTD.

World Bank. 2010. Ethiopia: Economics of adaptation to climate change. Washington DC: The World Bank Group.

World Meteorological Organization (WMO). 2003. Integrated Flood Management Case Study1Ethiopia: Integrated Flood Management. In WMO/GWP Associated Programme on Flood Management, Technical Report, 1-15.

You, GJY., and C. Ringler. 2010. Hydro-Economic Modeling of Climate Change Impacts in Ethiopia. IFPRI Discussion Paper No. 960. Washington DC: International Food Policy Research Institute (IFPRI).

\section{Submit your manuscript to a SpringerOpen ${ }^{\circ}$ journal and benefit from:}

- Convenient online submission

- Rigorous peer review

- Immediate publication on acceptance

- Open access: articles freely available online

- High visibility within the field

- Retaining the copyright to your article 